\title{
Andrés Bello, historiador de la lengua. Sobre el Cantar de Mio Cid
}

\author{
Juan Antonio Frago* \\ Universidad de Zaragoza, España
}

\begin{abstract}
Resumen
La inagotable dedicación de Bello al estudio y sus ansias de conocimiento en distintas ramas del frondoso árbol de las ciencias humanas le permitirían producir en su fecunda vida obras que lo consagraron como excepcional polígrafo y guía intelectual de muchos americanos en el siglo XIX. Seguramente la primera inclinación que el singular caraqueño tuvo fue la de historiador, si bien por razones perfectamente explicables no llegó a desarrollar una labor continuada en el campo de la historia de la lengua, ni tan lograda científicamente como sus excepcionales condiciones hubieran augurado. Sin embargo, su edición y anotación del Cantar de Mio Cid tiene aspectos de gran modernidad y son manifestaciones del genio lingüístico de Bello, que con esta obra filológica aportaría estimable ayuda a la que décadas después consagraría a Menéndez Pidal.
\end{abstract}

Palabras clave: cultura lingüística americana, Bello filólogo, Bello y Menéndez Pidal.

Para correspondencia, dirigirse a: Juan Antonio Frago Gracia (jafrago@unizar.es), Departamento de Lingüística General e Hispánica, Facultad de Filosofía y Letras, Universidad de Zaragoza, Pedro Cerbuna 12, 50009 Zaragoza, España. 


\title{
Andrés Bello, language historian. On Cantar de Mío Cid
}

\begin{abstract}
Bello's inexhaustible dedication to study and his longing for knowledge on the various branches of the luxuriant tree of human sciences allowed him to produce, during his prolific life, works that confirmed him as an exceptional polymath and intellectual guide of many Americans in the 19th century. Most certainly he initially had a leaning towards history, even though because of perfectly understandable reasons he could not develop a continuous activity in the field of language history, as scientifically achieved as his exceptional qualities would have predicted. Nevertheless, his edition and annotation of Cantar de Mio Cid shows aspects of great modernity and are the expression of Bello's linguistic genius, who with this philological study contributed significantly to Menéndez Pidal's work recognition decades later.
\end{abstract}

Key words: American linguistic culture, Bello the philologist, Bello and Menéndez Pidal.

Recibido: 19/01/15 Aceptado: 13/03/15

\section{NOTAS INTRODUCTORIAS ${ }^{1}$}

1.1. Lo más logrado que en su faceta de historiador de la lengua y filólogo salió de la generosa pluma de Bello fue la preparación para una edición anotada y provista de enjundioso prólogo del Cantar de Mio Cid, que vería póstumamente la luz en 1881, sin que pudiera darle una última mano ${ }^{2}$. La lectura del Prólogo que a su estudio pone Bello descubre su gran interés por "la historia del lenguaje y versificación castellana", aunando, lo que por

\footnotetext{
Del proyecto de investigación FFI2013-45985-P del Ministerio de Economía y Competitividad.

2 Es la que manejó Menéndez Pidal, y a la que remito por las páginas donde se menciona el lugar de cada pasaje que el filólogo español cita de Bello; de esta manera ahorro la acumulación de números en mi texto. Asimismo tengo en cuenta el Prólogo de la selección hecha por Jaksic, Lolas y Matus Olivier (Bello 2013), útil por sus notas y por los textos bellistas que lo acompañan, acertadamente compilados los de carácter histórico en el apartado de "Estudios literarios y filológicos", particularmente, en lo que al Cantar de Mio Cid toca, los "Apuntes sobre el estado de la lengua castellana en el siglo XIII" (129-151).
} 
desgracia entre nosotros no es frecuente hoy, las facetas lingüística y literaria en el estudio filológico, y reconociendo noblemente su gratitud a Tomás Antonio Sánchez "por sus apreciables trabajos", a la vez que justificaba la arriesgada y penosa tarea que él había emprendido (2013: 193):

El que yo he tenido en la presenta obra parecerá a muchos fútil y de ninguna importancia por la materia, y otros hallarán bastante que reprender en la ejecución. Favoréceme el ejemplo de los eruditos de todas naciones que en estos últimos tiempos se han dedicado a ilustrar los antiguos monumentos de su literatura patria, y disculpará en parte mis desaciertos la oscuridad de algunos de los puntos que he tocado.

El retraso hispánico en este campo filológico era por entonces muy considerable, sobre todo en el aspecto lingüístico, y Bello era consciente del riesgo que corría al adentrarse en el comentario de un corpus como el Mio Cid, no "con sus facciones primitivas, sino desfigurado por los juglares que lo cantaban, y por los copiantes que hicieron sin duda con ésta lo que con otras obras antiguas, acomodándola a las sucesivas variaciones de la lengua..." (174). También habría que contar con la falta de preparación de Bello como historiador de la lengua, algo común en el mundo hispánico de su época, defecto que se hace evidente en su consideración de la diptongación de las breves latinas tónicas en castellano y en alguna que otra cuestión más, como respecto de la evolución del artículo definido en la sincronía de los siglos XII-XIII.

Pero Bello tiene no pocos destellos de auténtica perspicacia filológica, verbigracia cuando trata de la composición etimológica del verbo ser (179180), o cuando rechaza el supuesto uso de la -e paragógica en lidiare, canale, Campeadore, razone (180-181): notable cosa es que Menéndez Pidal en las Adiciones sostuviera que en el "lenguaje español del siglo X" las voces con -e paragógica fueran "formas corrientes de lenguaje" (1178). Bello advirtió tanto la acentuación originaria de vío como el recurso a la apócope de la - $e$ a efectos métricos, pues "era lícito suprimirla o usarla como de ningún valor en medio de verso" (190): para esto, cfr. n. 11. Y desde luego un gran acierto del polígrafo americano al tratar del Cantar de Mio Cid fue atribuir a sus sucesivos copistas los cambios que experimentó desde el original, cuya composición no creía anterior al año 1200. En estas cruciales cuestiones disentiría de él en su obra Menéndez Pidal, y al contraste entre los dos autores se atiende en lo que sigue ${ }^{3}$.

\footnotetext{
3 El estudio de Menéndez Pidal se citará por páginas, por ser consecutivas en sus tres volúmenes. El poema cidiano se mencionará por Cantar, Mío Cid y CMC, a fin de evitar la
} 
1.2. Evidente es la erudición que en este Prólogo demuestra Bello, insaciable lector, con referencias a diversos autores y textos tanto literarios como de otra índole, incluso el fuero o "privilegio" de Avilés, y con conocimientos de historia externa muy apreciables, algunos de los cuales esgrimió en apoyo de sus tesis sobre el Cantar, así el referente a las luchas entre almorávides y almohades, para afirmar su idea sobre la datación del poema épico, interpretación con la que discreparía Menéndez Pidal. El bagaje erudito que trabajosamente allegó Bello aparece en todos los estudios reunidos por Jacsic, Lolas y Matus Olivier para acompañar a su Prólogo cidiano: el primero (111-120) basado en el saber del francés antiguo y su literatura, el segundo (121-128) en el del latín clásico y medieval, ambos aparejados con apoyo de datos de historia externa a la lengua y a la literatura. No parece, pues, sino que al ilustrado joven que de Caracas partía hacia Europa en misión oficial ya lo acompañaba la pasión por la historia, que tendría ocasión de acendrar con lecturas antes imposibles durante su obligada permanencia en Londres ${ }^{4}$.

En su "Literatura castellana" (153-172), formado por dos artículos periodísticos que Bello publicó en 1834, maneja argumentos que en parte son los del Prólogo, pero también otros, aunque el Cantar continúa siendo hilo conductor de estas páginas, para cuya composición en ellas propone la data de "hacia 1230" (159), nada inverosímil por lo demás. Pero su vena más puramente lingüística donde más encauzadamente fluye es en los "Apuntes sobre el estado de la lengua castellana en el siglo XIII" (129-151), centuria por cierto en la que para él se escribió el $C M C$, texto este al que se refieren todos los fenómenos idiomáticos y rasgos grafémicos considerados en dicho informe, junto con otros refuerzos documentales, de Berceo sobre todo. Se aprecia aquí el tratamiento tan diverso en extensión que Bello da al "Valor de las letras" (129-132) y a las "Afecciones gramaticales de la lengua" (133-151), a diferencia del que mucho después aplicaría Menéndez Pidal en su gramática histórica $(1980)^{5}$. Y en la parte de letras y sonidos, sin que

reiteración formal; sus versos llevarán la abreviatura $v$., no cuando no hay riesgo de que se confundan con menciones de las páginas pidalianas.

4 Aunque no fuera suyo el libro que se presenta como primero de los impresos en Venezuela, Calendario manual y guía universal de forasteros en Venezuela para el año de 1810 (facsímil incluido en Bello 2002), en la línea de otros del mismo género que se publicaron en la América virreinal. Muy probable es que de su autoría sean las páginas del Resumen de la historia de Venezuela.

$5 \quad$ La primera edición de este manual es de 1904 y en él su autor introdujo correcciones y aumentos solo hasta la sexta, de 1940. La parte fundamentalmente de fonética evolutiva ocupa las páginas 1-201; la morfología el resto (203-338), pero sin sintaxis, con apreciable extensión para el nombre (203-248) y en todo con continuo manejo del aparato fonético. 
falten los aciertos y los rasgos de intuición lingüística, se evidencia la mala preparación del sabio caraqueño para abordar con solvencia estas cuestiones, mientras en la segunda parte, en la que también hay algún que otro error, su genio gramatical le permite extenderse con mayor seguridad en el análisis de la venerable canción épica.

\section{DEUDA DE LA EDICIÓN CRÍTICA DE MENÉNDEZ PIDAL CON BELLO}

La más extensa cita que de don Andrés Bello se encuentra en la obra completa de Menéndez Pidal sobre el poema cidiano es el siguiente pasaje, con el que comienza el capítulo II, Edición crítica del Cantar, de su volumen III:

El poema del Cid ofrece uno de los casos más difíciles que en la crítica de un texto pueden presentarse, ya que se conserva en un solo manuscrito, muy posterior a la fecha de la obra e infiel al estado primitivo de la misma. De aquí la gran divergencia de criterio que se observa entre los que han trabajado en la reconstrucción del texto.

El primero que la intentó fue Andrés Bello. Su edición del Poema del Cid, preparada casi toda entre los años 1823 y 1834, retocada algo en 1862, y abandonada después por el autor, salió a luz póstumamente en 1881, formando el tomo II de las obras de Bello, publicación oficial de la república de Chile. Tal edición es hoy todavía muy estimable por haber comprendido mejor que las siguientes el sistema de asonancias del poema, y por la mesura y acierto de las correcciones que introduce en el texto de Sánchez. Sus defectos radicales en considerar el lenguaje del Cantar como de comienzos del siglo XIII y en servirse de las Crónicas muy inoportunamente, son en parte explicables teniendo en cuenta que se trata de un trabajo antiguo, inacabado, y que no representa el pensamiento maduro ni las últimas ideas del autor.

Mientras la obra de Bello permanecía inédita, o aun después de publicada seguía desconocida para los que trabajaron sobre el Cantar, la crítica sistemática de nuestro texto se iniciaba en Europa, tras el débil ensayo de D. Hinard (1857), con el magistral estudio de Milá (1847). A este siguieron, con ocasión de la edición de Vollmöller, los trabajos fundamentales de Baist (1880, etc.), y de Cornu (1881, etc.). Desde Bello, no se había vuelto a publicar el poema sino reproduciendo fielmente las lecciones del códice único. Lidforss, para sus enmiendas, sigue en cuanto a la métrica la teoría de Milá, y en cuanto a las asonancias concomitantes, la de Restori (1017-1018). 
Si bien se mira, el maestro de la filología española muestra su consideración hacia el prócer de las letras americanas en tanto en cuanto corrigió con "mesura" algunas partes del texto cidiano del dieciochesco Sánchez, por cierto no su mayor mérito, dado la situación científica en la España del siglo de la Ilustración, pero sobre todo por "el sistema de asonancias del poema" del que Bello se sirvió para intentar la reconstrucción del corpus original, método del que claramente es deudor Menéndez Pidal, aunque no llegue a reconocer paladinamente las ventajas que le supusieron contar con semejante precedente.

\section{EN LAS ADICIONES Y ENMIENDAS DEL CMC PIDALIANO}

3.1. Ahora bien, en el aspecto fundamental, puesto que en buena medida de reconstrucción lingüística se trataba, la equivocación de Bello habría consistido "en considerar el lenguaje del Cantar como de comienzos del siglo XIII", porque Menéndez Pidal contra viento y marea, y, hay que decirlo, con algunos criterios lingüísticos en este punto insostenibles, nunca cedió en su pretensión de que el $C M C$ hubo de escribirse hacia 1140, algo, por otro lado, consecuente con la actitud del gran filólogo, renuente a rectificar aspectos importantes de su extensa producción ${ }^{6}$. Y recuérdese que estas Adiciones constituyen la última revisión que el gran filólogo e historiador español hizo de su amplio trabajo sobre el gran poema épico.

En la línea de lo que anuncia la inicial cita, a propósito del v. 1182, con el de los Montes Claros auyen guerra tan grand, Menéndez Pidal dice: "Bello

6 Sabido es que Menéndez Pidal fue muy reacio a admitir contradicciones a no pocos postulados suyos, que por otro lado en vida del maestro de la filología española apenas los estudiosos extranjeros se atrevieron a formular, y que fue reacio a modificar o a abandonar aspectos importantes de sus planteamientos lingüísticos, así el referente al seseo andaluz y su relación con el español americano, o el del influjo sustratista suditálico en las asimilaciones hispánicas del tipo -MB-> -m-, de imposible acción como ha documentado Alberto Vàrvaro, anticuada teoría pidaliana que continúa enseñándose en algunas universidades. Y su mismo estudio del Cantar muestra cómo hasta el final Menéndez Pidal sostuvo su pensamiento sobre el castellano de los siglos XII-XIII con argumentos difícilmente defendibles. Aparte queda la tremenda reprimenda que dedica a H. R. Lang: "El furor de contradicción ciega frecuentemente a Lang hasta el punto de quitarle la lucidez para ver las cosas más sencillas ¡ini aun durante el largo tiempo que para la reflexión da el examen de 88 versos!!... ¡Lamentable y risible!!” (sic) (esto ya en las Adiciones, 1209). 
repara en el anacronismo de suponer a los almohades coetáneos del Cid y de Yúçuf", para sin solución de continuidad dar el giro que lleva el agua a su molino: "esto no tiene nada de particular, si recordamos cómo frecuentemente en las chansons francesas se alude a sucesos contemporáneos del autor; lo notable es, por el contrario, el anacronismo que supone el recuerdo de la guerra africana, indicio de que el autor del Mio Cid era contemporáneo de ella" (1170). Es decir, se desdibuja la acertada observación de Bello para convertir el error simplemente temático en apoyo del arcaísmo lingüístico propugnado por Menéndez Pidal.

3.2. En realidad, la guerra africana entre los almohades de los Montes Atlas (los Montes Claros del CMC) y los almorávides, el rey de Marruecos del v. 1181) se produjo entre 1123 y 1146, el Cid murió el año 1099, por lo que en tiempos del Campeador los almohades no podían estar presentes en la Península. El error histórico es, pues, evidente, pero el filólogo español reafirma su tesis lingüística precisamente en dicho desajuste histórico: los hechos en cuestión no ocurrieron en vida del héroe castellano, pero la lucha a muerte entre las dos grandes tribus saharianas por el dominio de Marruecos terminaba por los años en que propone la composición de $C M C$, iniciándose la conquista almohade de España en 1147. De modo que mientras para Menéndez Pidal la supuesta coincidencia de la referida guerra, bien que en su mismo final, sería prueba de que el autor del Cantar era coetáneo de la misma, todo bastante tautológico, para Bello el anacronismo indica que se escribió más tarde.

La cuestión histórica es que en efecto los de Valencia pidieron auxilio al almorávide Yusuf ibn Taxufin, que no se la prestó, y lo narrado en los vv. 1180-1184 mezcla lo realmente sucedido en el cerco de la ciudad del Turia con hechos bélicos acaecidos en Marruecos decenios después. El razonamiento pidaliano de que "una vez extinguido el imperio almorávide, dominando los almohades ambos lados del estrecho, sería difícil que un juglar acudiese al recuerdo de que antes los moros formaban dos naciones, una en Marruecos y otra en Montes Claros...", presupone que el autor del $C M C$ hubo de ser un poeta popular, pero son numerosos los datos que en este corpus literario abonan la mano de un autor culto, que en fuentes escritas pudo conocer los enfrentamientos entre facciones del islam africano décadas después de que tuvieran lugar, introduciéndolos puntual, y anacrónicamente, en el relato cidiano. Ni mucho menos parece descabellada, pues, la hipótesis de Bello. 
3.3. Respecto a su reconocimiento de que "la explicación de la frase por la mañana prieta 'cerca de la mañana, al acercarse la mañana' me fue sugerida por Bello, a quien olvidé citar después de ampliar los textos en que prieto tiene sentido adverbial" (v. 1687: por la mañana prieta todos armados seades; pero en Bello este verso es el 1719), Menéndez Pidal a renglón seguido matiza: "Es posible el tomar prieto no en su sentido primitivo 'apretado, estrechado, acercado', sino en el derivado de 'oscuro'", apoyándose en el de noche prieta de San Juan de Ávila (1207). Pero es evidente que prieto no tiene sentido adverbial, sino que estará adverbializada la frase en que se inserta, por consiguiente los dos casos sintácticamente complementos circunstanciales de tiempo; y téngase presente que entre los americanos del siglo XIX, y desde mucho antes, la acepción 'oscuro, moreno', incluso sinónimo de 'negro', era común, no así en el conjunto del español de España. En su Glosario del Mio Cid, Bello equivoca la etimología, pero no la semántica, y en la interpretación de dicho verso relaciona esta voz con "la acepción moderna de color oscuro y casi negro que tiene este adjetivo" (2002: VII, 294).

3.4. Así, pues, en las Adiciones y enmiendas que como colofón propuso posteriormente Menéndez Pidal a su obra sobre el CMC (1165-1224) únicamente existen estas dos referencias a Bello. La primera, a propósito de cómo entendió este los vv. 1181-1182 en cuanto a la identificación del anacronismo temático y la fecha del Cantar, reitera el rechazo pidaliano a la distinta datación del sabio americano; luego está el reconocimiento, no sin reticencias, de la deuda que el filólogo español tenía con Bello respecto de la interpretación de por la mañana prieta. Nada más que tenga que ver con la crítica del texto, la gramática, el vocabulario y el texto del Cantar. Veamos, pues, qué repercusión encontró el trabajo de Bello en el que mucho después abriría la puerta de la fama al fundador de la Escuela de Madrid.

\section{CITAS A BELLO SOBRE LA FILIACIÓN DEL CÓDICE ÚNICO Y SUS ENMIENDAS}

P. 15: Con cita a Bello en nota sobre "la frase datnos del vino [que] parece reminiscencia del verso atribuido a... Berceo: Bien valdrá, commo creo, un vaso de bon vino". 
En efecto, este verso pertenece al poeta riojano y la petición completa del colofón es dat nos del vino, si non tenedes dineros echad [a]lá vnos peños. En la edición crítica, Menéndez Pidal termina el $C M C$ en el v. 3730, en este logar se acaba esta razón, y anota: "Suprimo el éxplicit de Per Abbat, del año 1307, y el éxplicit posterior" (1164); es decir, el de la petición de recompensa, que precedentemente incluye en el todo atribuido al copista: "El resto del éxplicit es bien claro. Pedir vino en pago de una obra literaria era corriente entre poetas, recitadores y copistas, y también es conocida la costumbre de dar al juglar, en vez de dinero, prendas que lo valiesen" (17). La satisfacción y el don, ofrecido o solicitado, al término de la composición de un libro o de su penosa copia fue algo común en el Medievo, y entronca con lo que en la antigüedad latina significó la frase hecha excipit liber, corriente al final de tantos códices, así el del aragonés In excelsis Dei Thesauris o Vidal Mayor, de los últimos años del siglo XIII, "Laus tibi sit semper, Criste, quoniam liber explicit iste" (f. 277r), de alguna manera similar al v. 3731 del Cantar: "Quien escriuió este libro dél Dios parayso, amén!", solo que en el poema cidiano para sí la solicita el copista, y sobre el pergamino navarroaragonés es la simple satisfacción por la terminación de la obra, adornada de preciosas miniaturas, en forma de gratitud a la divinidad. Cuestión esta que tiene que ver con el nivel profesional del amanuense, con la calidad del material escriturario y con la condición social y económica de quien hacía el encargo, también con el tema del traslado: el del $C M C$ permite la solicitud de don espiritual y material para el copista, no así en un tratado jurídico como el Vidal Mayor. En el texto cidiano sigue la identificación Per Abbat le escriuió... (3732), y en el forense con letra libraria un Iste liber scripsit Michael Lupi de Çandiu, y otra pluma de elegantes y finos rasgos superpuso la enmienda gramatical istum librum (Frago 1989: 112) ${ }^{7}$.

\footnotetext{
Miguel López de Zandiu fue un importante notario pamplonés, quien mandó hacer para su uso tan preciado códice, y al que el amanuense a sueldo laudatoriamente le concede su hechura. Porque un notario nunca pondría scripsit en lo que fuera obra de su pluma, sino el verbo en primera persona, quién sabe si lo mismo vale para el Per Abad del Cantar, como sendos escribanos públicos de Sevilla pusieron "Ego, Remón Pérez scriptor Sibille, scripsi $\square$ sum testis" y "Ego, Michael Pétriz, scripssi et sum testis" (Frago 2002: 316, 322). Tampoco cometería tal personaje el error gramatical arriba señalado, ni la falta que supone poner quonian por quoniam: en el códice se lee qin con signo de abreviatura, que Tilander desarrolla quoniam, y también el estudioso sueco, cuya obra resulta todavía hoy de inexcusable consulta, introduce el vocativo en el éxplicit en que no figura, pero aduce ejemplos semejantes de otros códices europeos, en los cuales consta Christe, así este: Laus tibi sit, Christe, finitur enim liber iste (1956: 543). En cuanto al berceano "bien valdrá, como creo, un vaso de bon vino", el poeta riojano evidentemente no pide como copista, sino haciéndose eco de un extendido tópico y como rasgo de concesión popular.
} 
Realmente la discusión en torno al fragmento final del códice cidiano preocupa sobremanera a Menéndez Pidal, pues en su explicación se ventilaban cuestiones que afectan a la autoría y a la datación del $C M C, \mathrm{y}$, así, tras exponer opinión erudita que hace coincidente con la suya, dice: "A pesar de estos razonamientos, la mayoría de los autores, entre ellos Gayangos, Bello y D. Hinard, creyeron que el tal Per Abbat era simple copista, y que la fecha de su copia era 1307, habiéndose raspado maliciosamente una de las CCC para dar más antigüedad al manuscrito" (13). Es evidente que para Menéndez Pidal el problema de la datación del $C M C$ era absolutamente primordial, por lo cual lo retomará al principio de sus postreras Adiciones $y$ enmiendas, en las que se han visto las dos referencias a Bello como su principal razón de ser:

Al tratar la fecha del Cantar solo he expuesto los argumentos en favor de una data algo precisa, y ellos no adquieren pleno valor sino unidos a otros en favor de una fecha vaga, si bien muy antigua. Estos segundos los dejé dispersos en mi obra, a causa de lo cual no fueron tenidos en cuenta por una opinión contradictora de la fecha; esta opinión, aunque muy descuidada en tal materia, no debe ser desatendida y por eso amplío aquí lo expuesto arriba (1165).

Pág. 19: "Bello dice que el Cantar se escribió a principios del XIII y más cerca de 1200 que de 1250; se funda en el lenguaje del texto y en los errores históricos que contiene, v. gr., el de los infantes de Carrión".

P. 23: Del verso Ipse Rodericus Mio Cidi saepe vocatus del Poema de Almería, su "saepe por semper es corrección de Bello... exigida por el metro..., más abajo corrijo verum (la edic. virum) como hacen Bello, G. Paris y Konrad Hofmann".

P. 25: "Pero si no es dudoso que el Poema de Almería se refiere al Cantar de Mío Cid, pudiera referirse a una forma del mismo, anterior a la que conocemos, y ser la actual una mera refundición de aquella, como creía Bello, fiel a su idea de que el Cantar conservado había sido escrito hacia 1200". Y en nota: "Bello cree que el Poema de Almería se refiere a un Cantar de índole más histórica que el conservado, y que «fue recibiendo continuas modificaciones e interpolaciones en que se exageraron los hechos del campeón castellano... Cada jeneración de juglares tuvo, por decirlo así, su edición peculiar, en que no solo el lenguaje, sino la leyenda tradicional, aparecían bajo formas nuevas. El presente Poema del Cid es una de esas ediciones»". Luego vienen los matices pidalianos.

P. 26: "La oración de Guibelino en el Siège de Narbonne, también del XIII, que trae Bello, se parece más a la de doña Jimena, pero no da nombre a los Reyes (Magos); así, los nombres de estos faltarían en el Cantar". 
P. 53: Respecto a un importante punto del itinerario cidiano indica Menéndez Pidal que "el juglar se representaba sin duda el robredo de Corpes, no tan lejos al Sur de Atienza, sino como a una jornada de San Esteban... Puede, según esto, pensarse que el robredo del juglar debía caer hacia Castillejo de Robledo, pueblo situado 25 kilómetros Oeste de San Esteban". Y en nota: "La misma suposición hace Bello: «acaso no estaba lejos del pueblo que hoy se llama Castillejo de Robles» (sic). No halla dificultad alguna en esta suposición, pues no tiene noticia del Robredo de Corpes de la provincia de Guadalajara".

P. 59: "El error del verso troçieron Alcoçeva, a diestro de SantEsteuan de Gormaz (2875) es manifiesto, pues estando Alcoceva al norte del río, no puede caer a la derecha de San Esteuan ni de Gormaz, y debe leerse a diestro dexan Gormaz [en nota: "La corrección la había hecho ya Bello, aun sin saber la situación de Alcoceva", "y en 2843 (edición paleográfica vinieron a SantEsteuan de Gormaz, vn castiello tan fuert; edición crítica vinieron a Gormaz, un castiello tan fuert) Bello hace también en este verso la verdadera corrección"]. Respecto de este 2843 el cambio, hecho antes por Bello que por Menéndez Pidal, parece justificado, pues varones de Sant Esteuan se lee en 2847 y 2851, y el 2845 es A Sant Esteuan el mandado legó.

Pero que "el original pondría a diestro desan Gormaz [en nota "así se escribe desaron, por ejemplo, en Santo Domingo, 480"] y Per Abbat, o cualquier otro copista, resabiado por la frecuente mención que el Cantar hace de San Estevan, añadió de santEstevan" requeriría mayor determinación filológica. En efecto, en dicha composición berceana, de hacia 1236, aparece este desaron, aunque habría que determinar si se trata del códice transcrito en vida del autor o del manuscrito posterior, teniendo en cuenta asimismo que en texto de los Milagros son frecuentes formas como disso, dissiero, issiéli, ejemplos de $s s$ equivalente a $x$, por consiguiente muy posteriores a la datación que Menéndez Pidal defiende para el CMC. Sería raro, desde luego, que solo registrara el corpus cidiano la ese alta por $x$ en dicho verbo, y en ninguna otra voz romance, sí en los hidrónimos aragoneses Salón 'Jalón' $(555,577$, etc.) y Siloca 'Jiloca' (635), de étimos árabes, también con grafía $x$ - en fuentes medievales de Aragón.

P. 78: "Bello advertía que el Cantar de Mio Cid estaba escrito en tres clases de versos: el alejandrino, como dominante, con dos hemistiquios de siete sílabas y acento en la sexta; el antiguo endecasílabo francés, compuesto de dos hemistiquios de cinco y siete sílabas, y raras veces el enneasílabo, todos imitados de la poesía francesa". En nota acoge literalmente lo indicado por Bello ("No creo que se haya advertido hasta ahora que la Jesta de Mio Cid está escrita en diferentes jéneros de metro"), y añade que el americano "descubre igual mezcla en la Crónica rimada y cree que esos tres metros 
se imitaron de la poesía francesa... Expone algunas causas aparentes de irregularidad en el metro, con el uso extremadamente libre de la sinalefa y sinéresis..., y la posibilidad de suprimir la $e$ final inacentuada... Además, el uso arbitrario del artículo definido antes de un posesivo (sus fijos o los sus fijos), uso que los copistas alteran sin atender al metro". Se mejoraba así, reconoce Menéndez Pidal, los planteamientos de Diez y Wolf, aunque después el filólogo español pasa a desarrollar otras consideraciones de versificación a partir de que "la teoría de la imitación métrica francesa perdió terreno al descubrirse la existencia de una gran poesía épica indígena de Castilla" (80).

P. 117: "Entre los versos de asonante $o ́$, hay 34 casos de $o ́-o$, todos menos uno, constituidos por la repetición de dos nombres propios: Alfonsso... (30 veces), y Iherónimo... No obstante algunas correcciones en $o$ se imponen con tal evidencia que nos quitan la confianza en los otros casos de corrección no tan clara; así sueño ha de cambiarse, según las crónicas, en visión; esfuerzo en una disparatada errata por effurción, y los 30 casos de Alfonsso se destruyen con la anticuada forma Alfón". En nota: "Los críticos piensan de modos diversos respecto a esta corrección. Bello escribe Alfons en el Cantar, pues, p. 267-268, conoce de esa forma «infinitos ejemplos» (serán sin $-s$ ), bastándole citar la relación Compostelana de los hechos del Cid".

Pero no explica Menéndez Pidal por qué en su tratamiento de este nombre propio (452-454) no atestigua ningún Alfón, y sí un Alfons del siglo XII, no estaba tan equivocado Bello por consiguiente, y en las Adiciones (1177) se ve obligado a reconocer: "La forma Alfón, que aquí prefiero a Alfonsso, no debió ser la propia del original... Ya lo reconozco en la página 454". Aunque no es así, pues en ese lugar simplemente en muy posterior nota remite a la citada adición, y hay que decir que con equivocada remisión, lo cual es muy frecuente en quien se encargara de hacer los envíos a las Adiciones. Todavía quedan por señalar dos cuestiones más en este caso: la primera es preguntarse cómo el copista podría haber "remozado" un arcaico, y no documentado Alfón en Alfonso (¿entre 1140 y qué otra fecha?); la segunda, por qué el filólogo español no aprovechó su obligada rectificación para aliviar su anterior sarcasmo sobre Bello.

P. 142: Respecto al resultado de la Ŏ tónica latina en el $C M C$, la percepción pidaliana es que "el diptongo que escribe Per Abbat es, pues, el mismo que hoy día", pero que las asonancias demuestran que la rima se establecía con ó en los derivados de fonte, forte, morte, etc. "Los críticos explican este hecho unánimemente: Sánchez fue el primero que reparó en él y concluyó que el autor debía pronunciar: fonte, morte, fonte... Esta solución le parecía evidente a Bello, quien, sin embargo, no tomaba la ausencia de la diptongación por signo de gran antigüedad, pues creía que Berceo 
tampoco conocía el diptongo, ya que en sus poesías siempre ué consuena consigo mismo y no con é [en su Prólogo dice Bello: "en ninguna de las rimas de este copioso escritor consuenan vocablos acentuados en ué con vocablos acentuados en $o ́$ : los primeros asuenan solamente entre sí' (2013: 180)], no siendo así en el Alexandre ni en Juan Ruiz". Y añade una nota innecesariamente despectiva hacia Bello, habida cuenta de los años y de las condiciones académicas en que el americano se refirió a este fenómeno evolutivo. Todavía más: "en la misma obra (de opiniones vacilantes por no haber recibido del autor la última mano), dice en la p. 310 que debía pronunciarse óe, acordándose de las palabras portuguesas foi, pois, moiro (que no son casos de diptongación de Ŏ), y establece la serie: fonte, fointe, foente, fuente". Bello, efectivamente, no cayó en la cuenta de que bon en Berceo era latinismo, explicable en época de dominio de la scripta en latín, pero tampoco Menéndez Pidal se libró de tal desenfoque, por el que tiene algún disparatado apunte, y su tesis sobre el diptongo /wo/ en el corpus cidiano ha sido generalmente desechada.

Evidentemente, Bello estaba equivocado al suponer que en tiempos de Berceo no "se había verificado la transformación de la vocal en diptongo", llevado por su servidumbre al criterio de la asonancia y condicionado por su autodidacta formación en gramática histórica, disciplina escasamente conocida en aquel entonces, lo que no significa que ignorara la rima consonante del mester berceano ("sustituyendo al diptongo ue la vocal $o$ del que se origina, subsistiría la consonancia"), y al querer explicar la disparidad que en este aspecto vocálico advertía entre el desaparecido original y su códice, apunta al fenómeno de la transmisión textual del $C M C$ en una perspectiva que, para otros muchos aspectos del texto épico, será validada en la práctica, no siempre en el reconocimiento expreso, por la moderna filología: "Los copiantes, dando a las palabras la pronunciación contemporánea, pintando esta pronunciación en la escritura y haciendo así desaparecer la asonancia, nos dan a conocer que trabajaban sobre originales que habían envejecido cuando los transcribían" (2013: 180-181).

P. 168: "No habían aún dislocado su acento reyna... También los numerales [trisílabos] treynta, veynte, responden a la acentuación clásica" [y ofrece testimonios literarios]. Bello la da para el v. 872 [treynta cauallos al rey los enpresentaua]. "Adviértase que hallamos a la vez treinta y veint contados solo por dos sílabas y una", esto en el San Millán berceano. Pero opino que también en tal caso se debería hablar de original o copia, y de la data de esta.

P. 209: A propósito de la /e/ átona y de su apócope señala Menéndez Pidal que "sería aventurado suponer que además de la $e$ y $o$ corrientes existían otras $e$ y $o$ cerradas, en la sílaba protónica..." y que "acaso con más 
motivo podemos suponer que la - $e$ final era semimuda"; pero ya se sabe que cualquier vocal átona se pronuncia más cerrada que siendo tónica. En nota recuerda que Bello ya había entendido que la /e/ átona "se pronunciaba más débilmente que ahora por los casos de apócope y de síncopas en los futuros, como yazré", que el español critica no muy justificadamente, pues en la Disputa del alma y el cuerpo y el Auto de los Reyes Magos, de finales del XII o comienzos del XIII, el primer texto tiene dizré y maldizré, el segundo dizeremos y dizremos (Frago 2002: 275).

P. 235: "Un nominativo plural señaló ya Monlau en nadi NATI, aunque no es de ningún modo probable, por no ofrecer sentido de plural, contra lo que creen Bello, Cornu y Meyer-Lübke", pero el sentido de pluralidad de este indefinido, aparte del que todavía pudiera corresponderle por su origen de un nominativo, también está en su carácter de colectivo. Más adelante (259), Menéndez Pidal dice: "Nadi ["una alteración de nado, como otri, otrie lo es de otro"] se halla tres veces correctamente en serie asonantada en $a$, y dos en serie $a$ - $a$, donde debe corregirse"; sin embargo el v. 34 acaba en nada, sí en nadi el 589. Según esto, siempre la asonancia ha de dominar a la realidad textual y lingüística, aunque esta forma es la única que el códice trae, en interior o final de verso (768, donde "no tiene valor de plural en nadi nol diessen posada"). Corominas y Pascual rechazan la etimología pidaliana y también proponen un etimológico nominativo plural, en la secuencia (HOMINES) NATI (NON) 'hombres nacidos no...' (1980-1991: IV, 202-203). Y cfr. 8.1.

P. 237: "Pro, masculino, compárese Bello-Cuervo, Gram., nota 31".

P. 245: "Pero Vermuez, que está 8 veces como asonante $o ́$ ha de corregirse, no en *Bermoez, como supone Bello, sin documentar esta forma, sino en *Vermudóz..." Pero ninguno de los dos tiene razón, y Menéndez Pidal añade en nota: "No tengo ejemplos de la forma *Vermudoz, pero ni los creo necesarios, en vista de los análogos de la nota penúltima", argumento claramente pro domo sua.

P. 288: Sobre las variantes verbales en -ir y -escer, Menéndez Pidal señala que "el caso es curioso, aunque no muy significativo" y critica que "por simple descuido" Bello trate con desbarato esta cuestión y diga que "grado es en El Cid una exclamación que significa: gracias!"

P. 308: En el v. 2474, grant fue el dia la cort del Campeador, "Bello quiere que sea el día equivalente a 'aquel día' y lo califica de locución francesa", "pero creo deba leerse por la cort, y sea expresión análoga de tan buen día por la christiandad", y Menéndez Pidal así lo pone en su edición crítica, cambiando también el fue del códice por fo, creyendo esta forma más arcaica. En Montaner se mantiene fue y se añade en a cambio del pidaliano por. 
P. 311: Sobre el uso de don con el apellido, entonces en forma plena, se apoya en la Gramática de Bello.

P. 313: "Sánchez, y según él D. Hinard y Bello, no leyeron la conjunción" de "Teuar $\square$ el pinar" (v. 971).

P. 319-320: Del verso obrado es con oro, fecha por razón (3091), admite el análisis de Bello con fundamento gramatical ("esto es: relumbran por donde están; entendiéndose el nominativo huebras envuelto en el participio obrado", y en nota: "Esta me parece la única explicación compatible con el plural parecen. Se han buscado otras..."

P. 327-328: En "el dativo del pronombre personal tiene también valor posesivo en: amigol sodes (1528)..., otros ejemplos: Dios le abrá el alma (1705)", se apoya en Diez y Bello, con referencia a su Gramática, donde el amanuense dice: "Nace el dativo superfluo de la propiedad que tiene el dativo castellano de significar posesión: Se le llenaron los ojos de lágrimas".

P. 329: Respecto al v. 256 del códice, Aquellas uos acomiendo a uos, abbat don Sancho, Bello lo acomoda aquí las acomiendo a vos, y Menéndez Pidal: "siguiendo a este leeré: aquí vos las acomiendo" (así en su edición crítica), pues "aquellas se refiere a un sustantivo inmediato".

P. 332: De “que, adjetivo 'cuanto' 'muy grande' 695 [que priessa va en los moros, e tornaron se a armar], Bello corrige ja qué priesa van los moros tornándose a armar!", que Menéndez Pidal no sigue en su edición crítica.

P. 336: "Por este significado de 'mucho', se usa tanto en las enumeraciones..., características de la poesía épica..., más ejemplos en Bello".

P. 356: "En 2059 [catándol sedie la barba, que tan aynal creciera] el asonante exige creçió (Milá, Bello, etc.), en vez del pluscuamperfecto", y así está en la edición crítica pidaliana.

P. 361: "En las oraciones de gerundio, este no precede siempre a un sujeto, atributo o complemento (comp. Bello-Cuervo, Gr. 1131): avn biuo seyendo 2153 ..."

P. 367-368: "Fuera de las oraciones condicionales, es más rara la elipsis: el qui comer; e qui no caualgue 421...". En nota: "Bello fue el primero que comprendió y explicó ampliamente estas elipsis de los versos 181 y 832 [pero no 421], por mala lección de Sánchez".

P. 374: "En 883, tres semmanas expresa tiempo breve indeterminado, ya que desde el destierro del Cid hasta la mensajería de Alvar Fáñez tuvieron que pasar varios meses, lo menos cinco o seis como calcula Bello, pues solo 18 semanas las pasa el Cid en ganar y defender Alcocer". 
P. 377: La preposición $a$ expresa "el modo o manera: a grant ondra ... No creo necesite corrección priso a espolonada 2383 [así en el códice]. Bello cree que «acaso debe leerse priso espolonada»".

P. 385: v. 3320, passé por tí, con el moro me off de aiuntar, en nota: "Bello, Volmöller y Restori ponen la pausa entre $t i$, con"; como hará Menéndez Pidal en sus ediciones paleográfica y crítica. En p. 1149, para el 3316 [Miembrat quando lidiamos çerca Valencia la grand]: "Bello, Cornu y Lidforss ponen este verso con interrogante".

P. 386: Sobre el v. 3345, en nota: "La mayoría de los editores nos equivocamos uniendo el sentido del verso 3345 con el siguiente, en vez de con el anterior... Janer, Sánchez y Bello tienen razón en dejar sin punto ni coma el verso 3344 unido al 3345 y este terminado con dos puntos". Naturalmente, aquí no es cuestión de una determinada aplicación ortográfica, sino de la comprensión temática y sintáctica del texto del códice.

P. 390: Para el sentido de simple copulación de entre, se aduce texto del antiguo francés en Bello. Asimismo, sobre entramos 'entrambos' se cita la opinión de Bello de que "se usaba al principio, si no me engaño, solo como nominativo", pero Menéndez Pidal lo rectifica con testimonios de Berceo y Juan Ruiz.

P. 392: Sobre que la disyuntiva $o$ "también sirve para encabezar una interrogación", en nota: "Bello interpreta sin interrogación..." el v. 3277, contra la apuesta de Menéndez Pidal.

P. 407: Sobre la colocación del pronombre átono entre los dos elementos del futuro que encabeza la frase, el 3389 del códice reza fazer telo dezir que tal eres qual digo yo, que Bello supuso fazert' helo decir y Menéndez Pidal lee fazer telo [he]dezir, reponiendo el supuesto olvido del auxiliar, que ya está en lo entendido por el estudioso americano; de hecho, el filólogo español juzga "inadmisibles la interpretación de Bello y la semejante de Lidforss". También sobre el puesto de los pronombres átonos del infinitivo respecto del verbo regente, el 2967, podiendo yo vedallo, para Menéndez Pidal es ejemplo de una falsa asonancia traída por impertinente corrección del copista, que debe enmendarse en podiéndolo vedar yo: "Bello advirtió ya la necesidad de la corrección, pero contra la sintaxis del Cantar, puso podiendo vedallo yo".

P. 415: "Entre los adjetivos que se anteponen al sustantivo tan frecuentemente que, efecto de esta posición átona, viene a apocoparse, se debe notar la posposición en padres santos 360, que exige corrección para la asonancia, leyendo santos padres según Bello, Restori, etc." 


\section{EN LA EDICIÓN CRÍTICA DE MENÉNDEZ PIDAL. RESUMEN}

En su edición paleográfica no tiene en cuenta Menéndez Pidal sino las que tuvieron delante el códice único o una reproducción del mismo, decisión de todo punto de vista lógica. Pero en su edición crítica sí recurre a obras de diversos estudiosos, Bello entre ellos, sobre todo porque de lo que se trataba era de la "restauración" del original conculcado por descuido de los copistas o por sus adaptaciones a usos lingüísticos que no eran los vigentes en vida del autor, también como consecuencia de las varias incomprensiones de pasajes del corpus cidiano. De las referencias a Bello se ha dado cuenta en lo que precede, y en ellas Menéndez Pidal acepta "lecturas" del americano, así en la del v. 1182, salió de Muruiedro vna noch en trasnochada, que Montaner mantiene y el maestro de la filología española cambia por a trasnochar, "corrección de Bello"; del 1201 "suprimo con Bello, Restori y Lidforss (Myo Çid)", en el 3258 le toma el añadido prepositivo, "dezid ¿qué vos merecí ifantes de Carrión?" (1147); y asimismo coincide con él en 516, 605, 2215 entre otros, o anota sin rechazo enmiendas y adiciones al códice único de Bello distintas a las suyas, en 491, 1385, 1411, 1418, 1419, 2211, 3275, etc. Algún detalle documental más, aparte de los señalados, enfrenta a Menéndez Pidal con Bello, así sobre la fecha de la venta de una heredad de doña Jimena en Valdecañas, defendiendo el español la de 1113 y dando por errada la de 1119 del americano, que habría seguido una fuente viciada (767).

Sin embargo, las críticas pidalianas al sabio americano también pueden ser acerbas, ejemplos de ellas se han señalado, especialmente cuando la discordancia afectaba a la antigüedad de la composición del $C M C$, a ultranza mantenida por el español en su hacia 1140, y a cuya defensa se dirigieron sus recursos argumentales. Incluida la aserción onomástica de un “*Vermudóz, exigido ocho veces por la rima..., muy propio de los siglos XI y XII, pero inusitado en el XIII", que tampoco se halla en interior de verso y del que no encontró testimonio alguno en fuentes de estos siglos, pero con el que indebidamente ironizó respecto de Bello (cfr. P. 245, de 4.).

\section{UN APOYO DOCUMENTAL MUY CONDICIONADO}

6.1. No estará de más detenerse en la argumentación diacrónica que mantiene Menéndez Pidal en las Adiciones, que realmente suponen el colofón de su 
obra, a propósito del principio que sostiene el armazón del trabajo que lo encumbró científicamente antes de que publicara sus Orígenes del español en 1926, que en capitales cuestiones atiende a la inamovible convicción de que la composición del $C M C$ estuviera hecha hacia 1140, lo que probablemente condicionó su empeño en reconstruir el lenguaje del Mio Cid desde el códice único del siglo XIV. De ahí que el posesivo tus (las tus mañas) del v. 3315 del códice, y así en otros casos, en la edición crítica lo haga tues, siendo que la primera forma ya está atestiguada en el siglo XII, o que el numeral LXV del v. 1419 lo transcriba en su versión más arcaica ("sessaenta e çinco"), o sus forzadas monoptongaciones verbales, como la de fuéremos (v. 1409 del códice), ya con ue en su formación etimológica, contrahecho fóremos en la edición crítica, etc.

Pues bien, a continuación de la última cita traída a colación a propósito de su disenso con Bello sobre la cuestión de los Montes Claros (cfr. 3.1.), Menéndez Pidal afirmará: "Hoy soy menos escéptico que en 1908 respecto a la posibilidad de conocer el lenguaje primitivo del Cantar", dicho esto con el apoyo del enfeudamiento de Alcozar, que su particular análisis le dicta (1172). Este texto, que he llamado "castellano de frontera", fechado por Canellas López entre 1151 y 1156, Menéndez Pidal lo data en 1155, es un original con sus doce primeros renglones debidos a un servidor de la cancillería del señor de la honor de Soria, Fortún López, o en su defecto de la del obispo de Osma, y las dos últimas líneas de Diego Pérez de Fuentealmejir, si no las escribió un amanuense suyo, lo que me parece lo más probable. A este importante texto dediqué un extenso análisis (2002: 213-233), del que ahora me fijo únicamente en los datos de que Menéndez Pidal se sirve para apuntalar su consideración cronológica del $C M C^{8}$.

6.2. Asegura el filólogo español que "este documento está en romance, sin resabios latinizantes", dicho esto del que empieza con un formulario In Dei nomine, y que contiene formas como archidiacon-archidiagno-archidigno,

\footnotetext{
8 La transcripción de Canellas sobre el autógrafo lee moriese, donde Menéndez Pidal puso moriere, con todo acierto, pues efectivamente el original en igual contexto solo registra el futuro de subjuntivo. Pero seguir la suposición paleográfica de Canellas, la doblez perpendicular del manuscrito borró la última sílaba de este verbo, me llevó a proponer en este punto un imperfecto de subjuntivo (223), no obstante que en la misma obra refiero la forma en -se de los textos medievales que en ella trato con el valor etimológico de pluscuamperfecto (301, 479). La forma en -ra aún llegaría a América intermedia de pluscuamperfecto e imperfecto de subjuntivo, o con el sentido de condicional compuesto, tal como está en Juan de Valdés.
} 
canonibus-canónigos, escripto, maleditos, sancta, seiamus-seyamos, tecto 'techo', construcciones absolutas como "manos iuntas por foro de Castiella", irado e pagado, tomadas de fórmulas del latín medieval, en el que fue frecuente el quod conjuntivo, con un solo registro aquí ante la corriente presencia de que; y está la latinización de Sancho en Sancius, amén del calco de la preposición supra 'además de' ante el demostrativo romance aquesto en " $\square$ subraquesto seiamus descomulgados $\square$ maleditos". Señala asimismo Menéndez Pidal que en la infeudación de Alcozar "la - $t$ verbal no falta nunca" (1203), pero la desinencia - $n t$ nunca aparece (lauran, poblarán, podrán), y en singular se hallan diod 'dio', foret-fored 'fuere'. No repara en la imposibilidad de que la $-t$ del lat. dedit pudiera haber dejado huella en diod, ni en la forzada latinización de fored ( $<$ fuerit), o en plegat, que supone la metátesis *plaicat, tampoco en los evolucionados esquollat 'escoja', prendrat, quisieret, ternat, tengat, forma esta predominante en el breve corpus, pero con una variante teingat, cuyo lexema presenta en el grafema ing la palatalización del nexo etimológico NY (teneat>teña).

No saca las debidas conclusiones Menéndez Pidal de que por los años de esta infeudación, pero también mucho antes, la diptongación estaba plenamente asentada en el primitivo castellano: la del resultado/je/ aparece con toda regularidad en atienda, atendiéremos, Castiella, castiello, quisieret, teniendo; la de /we/ en buelta 'vuelta', buena, bueno, quemo ('cuemo' desde el etimológico cuomo), fuerza, muerto, mientras que los aparentes casos de no diptongación, que en puridad son auténticos latinismos, se encuentran en expresiones forenses: "por foro ('fuero') de Castiella", "a tal foro qual el obispo le diod dOsma", esta incluso con hipérbaton, o en formularia enumeración de bienes, "terras, uinnas, casas, presas, ortos, tecto..."), que en tantos documentos notariales de la época se lee. De manera que su empeño en mantener muchos años después de su primera redacción del estudio y edición del Cantar, en 1908, que "todo nos lleva a confirmar que el poeta del Mio Cid usaba $u o$, más bien que $o$, como forma propia del romance literario" (1195), no deja de ser una grave distorsión de la realidad diacrónica del castellano.

6.3. Ya sería muy difícil, por no decir imposible, entender que en ningún momento de su historia en este romance poeta alguno haya podido servirse libremente de soluciones tan dispares como las de /wo/ y /o/, ni siquiera para la rima asonante, entre una no diptongada desde el étimo vocálico y su diptongación en forma sin atestiguación en el castellano de la época, en la que, y el mismo documento de Alcozar es prueba de ello, las vocales breves tónicas del latín se ven resueltas con sus soluciones modernas de esta lengua, 
de lo que incontables y muy anteriores muestran existen. Pero Menéndez Pidal, consciente o inconscientemente, supedita en estas cuestiones la autenticidad diacrónica a su inamovible primera creencia sobre la datación del poema cidiano, también cuando habla de "la vacilación entre fillo y fijo" (1172), y porque en el documento de Alcozar "no hay $j$ ", llega a suponer que "el resultado simplemente castellano del latín $l i$ o c'l, fijo, ojo, etc., que se halla en el manuscrito de Per Abat, debe ser una modernización" (1197). Ninguna aclaración añade el filólogo español a tan peregrina especie, pues ¿a quién se debería esa "modernización”?, de suponer es que a algún copista, y Menéndez Pidal sostiene que muy pocos tuvo el texto del Cantar: ¿alguno pudo ser capaz de sustituir la $l l$ por la $j$ sistemáticamente en varios miles de versos?

Pero esto es entrar en una discusión bizantina, pues el hecho incontestable es que tal concepción evolutiva es errónea. La comentada infeudación efectivamente no tiene $j$, sino esquollat 'escoja', fillo (2 ejs.), fillos, mullier, esta voz con la grafía típicamente aragonesa $l l i$, resultado palatal lateral navarroaragonés de los grupos LY, C'L, frente al de la prepalatal fricativa sonora que de ellos salió en castellano. El texto en cuestión es en su conjunto castellano, pero con evidentes rasgos propios del romance de Navarra y Aragón, no solo por vecindad geográfica, sino sobre todo porque la actual provincia de Soria estuvo bajo el poder de Alfonso I el Batallador, rey de ambos dominios, que la repobló con participación de súbditos suyos, e impuso dignatarios de su dependencia regnícola, en cuyas escribanías durante algún tiempo se mantuvieron formas y usos de los dos reinos orientales. Se trata, pues, de un corpus del "castellano de frontera", del que otros ejemplos hay en el Medievo hispánico, en el cual se verifican claros aragonesismos lingüísticos aparte del caso de consonantismo consignado, así como una inequívoca onomástica: donna Nauarra, Caluet 'Calvete', Iauna Ioan (vasco jaunak 'señor'), Roig ('Royo') Aragonés, Roig Malladón, de mallada 'majada', también con evolución navarroaragonesa, no castellana.

6.4. Así, pues, no debería haberse apoyado Menéndez Pidal en este diploma feudal con los argumentos con que lo hizo para defender a machamartillo su idea de un Mio Cid compuesto en 1140, y con los mencionados presupuestos lingüísticos, sino en todo caso para retrasar su redacción y probablemente también para cambiar su localización soriana. En realidad, el "envejecimiento" del Cantar se vio favorecido por ideas pidalianas que no tuvieron suficientemente en cuenta lo difícil que tuvo que ser el paso de una lengua escrita, durante tantos siglos solo latina, a otra hecha en romance, proceso que tardó tiempo en desprenderse de resabios de todo tipo arrastrados 
de la anterior costumbre escrituraria, así las desinencias verbales que se aprendían en la formación escolar y se mantuvieron en la práctica textual, en el rutinario quehacer del escritorio.

Por no atender a los serios problemas a los que hubieron de enfrentarse los poco doctos redactores en el avulgarado latín hispánico, y por reunir de manera indiscriminada formas con evoluciones muy dispares, se ha dicho que "el español primitivo carece de fijeza", e incluso se ha llegado a pensar en situaciones lingüísticas "caóticas" . Pero aun dejando de lado la amalgama de desajustes formales reunida desde dispares textos, tampoco todo lo "anómalo" que descubre la escritura del siglo XII y primera mitad del XIII puede trasladarse a lo que sería la lengua hablada de la época, pues en los textos claramente se aprecia la rémora del lento apartamiento desde el único modelo latino hasta entonces vigente, en un proceso en el que quedan huellas de la anterior situación cultural hasta que a lo largo del doscientos la scripta en romance cobra definitiva carta de naturaleza (Frago 1998).

\section{7. ¿ES POSIBLE LA RESTAURACIÓN DE UN ORIGINAL DESDE LA COPIA?}

7.1. Si el primigenio texto falta y si de él se conserva una sola copia, además distanciada en el tiempo, como es el caso del $C M C$, la reconstrucción siempre será problemática, y nunca indiscutible, porque el Traduttore, traditore con tanta o más razón puede aplicarse al copista, que, aun sin querer modificar el manuscrito que traslada, difícilmente se librará de sustituir alguna

\footnotetext{
9 "Coinciden en el habla formas que representan diversos estados de evolución. En León contendían las latinas altariu, carraria, las protorrománicas autario, autairo, carraira, las posteriores auteiro, outeiro, carreira y las modernas otero, carrera, sin que faltaran combinaciones como oterio, autero, outero, oteiro, etc.", y porque las Glosas Emilianenses en pocas líneas "ofrecen tres grados distintos de pretérito: el latino lebantaui, el intermedio lebantai y el romance trastorné", se concluye que "en medio de esta coexistencia de normas, al parecer caótica, la evolución lingüística avanza con pasos lentos, pero firmes" (Lapesa 1985: 160, 164). Lapesa sigue muy de cerca a Menéndez Pidal en la presentación e interpretación de estas formas, y en la aceptación de la existencia de "un latín avulgarado, escrito y probablemente hablado por los semidoctos". Pero aquí no cabe hablar de "normas", ni de un latín hablado por "semidoctos", sino de interferencias del romance de quienes se veían obligados a escribir en una lengua de cultura deficientemente aprendida algo parecido a lo que ocurrió en el latín merovingio.
} 
palabra o giro anticuado por lo que su arraigado uso le dicta en determinado momento, también por simple incomprensión de lo que había entrado en desuso, o por la misma dificultad de lectura. Así, respecto de prender, que se empleaba por el posterior tomar y que en el XIV experimenta un acusado retroceso en Castilla, "pues el ms. A de los Milagros de Berceo lo sustituye sistemáticamente por tomar (que a menudo no cabe en el verso)", y el amanuense del Marqués de Santillana "practica la misma sustitución en su ejemplar de la Primera Crónica General", según Corominas y Pascual (1980-1991: IV, 639). Y mientras la copia de 1417 de la Carta puebla que a El Puerto de Santamaría otorgó Alfonso X El Sabio aún mantiene ruas apartadas, en las que vivirían los extranjeros por privilegio real, quien hizo otra en la segunda mitad del XVI ahí entendió rentas aportadas (Frago 2002: 125).

En el Cantar, las dificultades se extreman, porque perdura en copia única, y entre su composición y la del siglo XIV sin duda hubo muchas, contra lo que Menéndez Pidal cree, muy probablemente no todas producidas linealmente, o desde unos mismos modelos, teniendo a mi parecer más razón Bello, aunque estrictamente no se refiera a la copia individual, que es lo que tuvo que haber, en su opinión sobre sucesivas variaciones en la transmisión del corpus cidiano (cfr. P. 25 de 4.). Ocurre también que Menéndez Pidal explica a base de hipótesis la relación lingüística entre el códice único y el original, para él necesariamente compuesto en tierras de Medinaceli hacia 1140 , de donde sería propio un diptongo /wo/, pero que "se conservaba en la lengua poética solo para la rima" (1019), para Lapesa "refundido" en los mismos lugar y fecha, "transcrito, probablemente de la tradición oral de los juglares a fines del siglo XII o comienzos del XIII, y conservado solo en una copia del XIV" (1985: 196). Pero "refundido" ¿de qué textos, latinos, romances o de ambas lenguas?, porque algún autor fija la hechura del Cantar incluso en 1120; y "manuscrito" de la tradición juglaresca, pero ¿entre 1140 y 1207 no habría habido otras transcripciones, y desde luego copias? Muy cuesta arriba se hace creerlo, como sin duda las hubo entre 1207 y el códice único en un poema de semejante importancia para Castilla.

7.2. A pesar de la bibliografía extraordinariamente extensa existente sobre el $C M C$, son muchos los interrogantes que todavía se suscitan a su respecto, empezando por el raspado de una $C$ al final del códice, o el hueco que en él queda, o por cómo se mantendría intacto el éxplicit desde principios del XIII hasta la redacción que conocemos. Está asimismo el papel de los juglares en la composición y transmisión del Cantar, y en relación con este problema se halla la opinión de Montaner de que "El colofón del recitador 
es una adición de otra letra del siglo XIV, tras el éxplicit. Como era habitual, el ejecutante pide una recompensa por su labor..." (1993: 688), antes este estudioso afirma que "el testimonio directo es el del colofón del intérprete, en el que se señala el fin de la lectura o recitación en voz alta, hecha con el códice a la vista" (316). O sea que un intérprete o ejecutante, ¿ ¿solo uno u otros más?, emplea el códice para su declamación y luego en lugar de pedir a su público la recompensa, que es genérica y tópica, se dedica a escribir muy regularmente la petición, que de memoria sabía, bien alineada a continuación del éxplicit (vv. 3734-3735 ). Pareciera, así, que fuera de su propiedad el manuscrito, que en tal caso inevitablemente habría sufrido la injuria del ejercicio juglaresco, y quizá otras anotaciones en el códice, del que Orduna sospecha que su copia "fue ordenada... como un manuscrito de trabajo o de consulta en un taller historiográfico del s. XIV" (1989: 7).

Mi opinión es que el códice se copió en un scriptorium postalfonsí, hipótesis que esbocé tras el análisis de las cacografías que contiene, y que serían compatibles con el estado del castellano en el mediodía peninsular, el de Sevilla sobre todo (2000). Resumiendo mucho, están los lapsus que probablemente son consecuencia del tratamiento andaluz de la /-s/: "lo myos amigos", "acusado seré de lo que uo he servido", "a todo lo cargaua", "los yfante de Carrión", "las arca", "moros de la fronteras", etc. Sobre /-r, -1/: cauagar, cuepo, Fenando, tonan, rehechos canónicamente con la superposición de la letra olvidada $(324,478,2721,2352)$, Albafáñez rectificado Albarfáñez (752, 826), también en Albarábarez (442). De la /-d-/: "mandó caualgar tos sos fijosdalgo" (1832), sobrescrito dos, y el corriente Vermúez en dos ocasiones lleva $d$ en el interlineado superior.

Lo que de innovación fonética estos rasgos gráficos sugieren se verifica en fuentes andaluzas de mediados del XIV con apreciable frecuencia. Igualmente los que conciernen al fenómeno seseoso, que por entonces, con sus particulares características, también se desarrollaba en francés, catalán y portugués. El quiçab del v. 2500 no puede darse simplemente como "forma etimológica, de quí sabe" (Montaner 1993: 252) o como una mera "equivalencia acústica", en solución pidaliana; de explicar çervicio, çerviçio (69, 1535), pero servido (73), no se ocupa Montaner, y para Menéndez Pidal es un caso de asimilación, de disimilación San Çaluador, añadiendo sin embargo que "son raras estas grafías, primer asomo del ceceo" (174). Aunque ya sabemos lo que para nuestro filólogo era este "ceceo", que desde luego no está en su "primer asomo" en el códice cidiano, y que el desliz $c$ por $s$ lo podía, y puede, cometer lo mismo el ceceoso que el seseoso.

Lo más sorprendente es que el topónimo Celfa (v. 646) en explicación de Menéndez Pidal que no rectifican sus Adiciones, fuera el turolense Cella "con la aspiración correspondiente a la $f$ - que usa el Cantar" (571), para 
Montaner "Celfa: posteriormente Celha y hoy Cella" (1993: 140), cuando en Aragón no se aspiró la /f/ ni de / $1+\mathrm{h} /$ se deriva una palatal lateral sonora; pero Selfa sí puede ser voz valenciana seseosa, ni la "aspiración que usa el Cantar" en absoluto se prueba en el topónimo al que Menéndez Pidal remite (180). En fin, estos datos se compaginan con otros de carácter general que afectan la evolución del consonantismo castellano en la época dicha, como son la alternancia de -ss- y -s en Asur Gonçález y Gonçalo Assúrez (3008), el cambio de -g- por -s- en el latinismo eclegia $(2239,2241)$, y en tijera sobre el etimológico tisera (1241), además de los tres registros de ge por se en "falssóge la guarnizón" $(3676,3679,3681)^{10}$.

7.3. Se nos presenta así el códice único muy distanciado de 1207, mucho más de 1140, hacia donde mira la restauración del corpus cidiano. En relación con la fecha más antigua, pero incluso con la segunda, están para en vez del primitivo pora (775), y el epentético fincar con numerosos registros, excepción hecha de un ficarán (455), reminiscente del texto arcaico. En cuanto a las series etimológicas de los posesivos mío, to, so / $m i, t u, s u$ hay numerosas interferencias, entre ellas mi amor, su vassallo (2905, 3141), "my coraçón e mi alma" (1605), sos mañas (2171), envejecidas en la edición crítica, sobre lo cual Menéndez Pidal dice: "la forma femenina mi mis, propagada al masculino, de lo que ya ofrece ejemplos Per Abbat, debe ser desterrada, pues aun en la segunda mitad del siglo XIII, los textos más correctos no contienen esta confusión" (256). Pero en la época alfonsí había quienes en el nivel culto mantenían la diferenciación etimológica con todo rigor y quienes trocaban los dos géneros (Frago 2002: 314-326), y las numerosas interferencias que en este aspecto gramatical registra el códice del Cantar no podrían darse con tal frecuencia en la segunda mitad del siglo XII, aunque algún caso aislado llega incluso al so cosa de las Glosas Silenses. Aquí es probable la intervención de varios copistas a lo largo de más de un siglo hasta el corpus de la Biblioteca Nacional.

Ahora bien, la reconstrucción del antiguo texto literario es tarea imposible si ha de regirse por rígidos criterios preestablecidos y con contraste histórico que pueda estar viciado. Se apoya así Menéndez Pidal en la comentada infeudación de Alcozar, pero en tal documento esquollat no es ejemplo del diptongo /wo/, sino de grafía $q u$ de $/ \mathrm{k} /$, conocida en textos de la época

10 De estas cuestiones me he ocupado al tratar de la formación del andaluz (Frago 1993), $\mathrm{y}$ en estudios posteriores. 
y posteriores: en el aragonés al sur de Huesca, en el romance de Navarra que hubiera podido influir en sus redactores, y desde luego en tierras de Medinaceli, nunca se ha atestiguado esta diptongación. Tampoco autoriza dicho manuscrito soriano a defender los cambios del diptongo /we/ del códice único por la monoptongación /o/ de la edición crítica pidaliana, ni siquiera tomando en cuenta el Auto de los Reyes Magos y la Disputa del alma y el cuerpo. Lo mismo puede decirse del mantenimiento de la /-t/ de la desinencia verbal, que no es sino latinismo, con mayor razón si se ve que el Auto solo dos registros tiene de ella (pudet, uinet), todos los demás sufijos con terminación vocálica (será, tomará, trae, uale, etc.), solución esta que es sistemática en la Disputa (Frago 2002: 254). En conclusión, y como hace años argumenté (2000), el códice único ofrece arcaísmos y latinismos que apuntan a coincidencias con los textos castellanos de finales del XII y principios del XIII, cuando seguramente se dio forma escrita al Cantar que a través de copias ha llegado a la que afortunadamente conocemos.

\section{LA SABIA INTUICIÓN DE BELLO EN SU LECTURA DEL CMC}

8.1. La restauración de textos medievales, que tanto interesa al filólogo literario, es inevitablemente conjetural, y nuestro poema épico presenta las mayores dificultades para lograrla. Menéndez Pidal advirtió que "si el metro del Cantar es todo confusiones, por el contrario el asonante se presta a un estudio más útil, a pesar de lo muy estropeado que está para el copista" (103); pero con esas confusiones de su métrica y con el estropeo no del copista, sino de muchos copistas, lo cual es de más graves consecuencias textuales, la rima no pasará de ser relativo criterio en la identificación lingüística del original. Inútil es forzarla a una antigüedad idiomática que solo el análisis de todo el corpus, sin condicionantes apriorísticos y con adecuados cotejos diacrónicos, podrá aventurar. De nada sirve que Menéndez Pidal constriñera un nadi del códice a un nadie "necesario" para la rima (P. 235, de 4.), siendo que nadie por primera vez lo atestiguo en único registro del Fuero de Cuenca, de la segunda mitad del XIV, y que este indefinido todavía en el XV tuvo escasa presencia en la lengua culta, que prefirió ninguno, aún popular para Valdés (Frago 2002: 360-361): Juan del Encina en sus versos alternaba las dos formas con fines métricos. 
El Mio Cid a cada paso obliga a elevarse del verso a cuestiones de mayor complejidad, como el 1392, "saluda uos myo Çid allá ond de elle está" 11 , y a arriesgarse a errores de bulto como el que Menéndez Pidal cometió al tratar de la evolución de $\mathrm{G}$ o $\mathrm{J}$ latinas ante vocal palatal, con resultado yente y "dialectal gientes... usual en América" (173), relación americana que no corrigió en sus Adiciones y que retienen algunos estudiosos del español de América, precisamente al tratar del de Chile ${ }^{12}$. Pero Bello, en la penuria científica y bibliográfica que sufrió en su faceta de historiador de la lengua, propuso una datación del Cantar que a la larga se impondría en la crítica cidiana, además de lo que supuso su aportación en materia de métrica en el momento en que la hizo.

8.2. Bello acertó en juicios gramaticales, así para el v. 2215 y en otras cuestiones antes señaladas, seguramente también en el 3316, ¿miembrat quando lidiamos çerca Valencia la grand?; hila fino al señalar el acento etimológico, tipo reína, veínte, y en más aspectos que aquí se han ido desgranando. Su apelación al Poema de Almería, que Menéndez Pidal mira con recelo, ha vuelto a activarse por la crítica, y en su trabajo queda impresa la lúcida perspicacia de quien, ansioso de saber, se afanó por enfrentarse con rigor a un corpus como el $C M C$, todavía hoy lleno de aristas para cualquier estudioso, más para quien para colmo no dispuso de una reproducción de su

11 Por un lado, si lo comparamos con el 1392, "Adelinó pora San Pero $o$ las dueñas están", con el arcaico locativo, presente en el Auto de los Reyes Magos, notamos que su sinónimo onde, innovación morfosemántica, está acorde con la implantación que este adverbio tuvo en el siglo XIV, pero también una vacilación entre apócope y forma plena, tal vez indicativa de que esta era la corriente en el castellano hablado. En el siguiente, la del segundo hemistiquio, "quandol vieron assomar", probablemente esté condicionada por la métrica, recurso vigente en toda la Edad Media, hasta Juan del Encina, Lucas Fernández y Torres Naharro, y es posible que el fenómeno no fuera solo de la lengua literaria, pues en 1615 el cronista peruano Huamán Poma escribe: "los tres hijos quel diesen sementeras y pastos" (Frago 2002: 430). Y Encina en su Poética castellana dice: "tiene el poeta y trobador licencia para acortar y sincopar qualquier parte o dición", como Juan de Mena, que en una parte ponía «que nol pertenece» y en otra «que no le pertenece»" (1496/1989: 5r).

12 Sin tener en la debida cuenta que el fenómeno americano en cuestión se da únicamente cuando a la consonante sigue una vocal palatal y que no afecta solo al fonema derivado de las antiguas prepalatales, sino también a la $/ \mathrm{k} / \mathrm{y}$ a la $/ \mathrm{g} /$ en igual contexto, por lo que, como repetidamente he advertido (1993: 438; 2008: 40-41), se trata de un caso asimilatorio, semejante al que G. Straka descubrió en francés antiguo. Se sabe que esta palatalización de la velar en diversos grados se da en otras partes de América, y extraña que algunos mantengan que esto consista en una cierta prolongación del reajuste medieval; pero más que la escueta mención pidaliana sin duda ha influido en ellos lo que al respecto expuso Lapesa $(1985: 378,546)$. 
códice. En sus comentarios sobre el Cantar demuestra el sabio caraqueño talante de historiador, y de romanista, pertrechado de no escaso conocimiento del francés antiguo y con apuntes de varias lenguas. El tema cidiano se reitera en sus manuscritos: será el Arzobispo D. Rodrigo. Sobre el Cid y el matrimonio de Rodrigo, será la Relación de los hechos del Cid anteriores a su destierro, o la carta que envía a la Real Academia Española reivindicando la pertenencia de unos versos de la Crónica a la Gesta de Mio Cid, con el silencio como respuesta por parte de Madrid, etcétera.

En su ingente obra, Bello manifiesta un espíritu de humanista. Partiendo de su conocimiento del latín, puede tratar Del ritmo y el metro de los antiguos y anotar de memoria, aunque incompleto, el virgiliano formosam resonare doces Amarylida[silvas] (quinto hexámetro de la Égloga tercera); hacer etimologías, así la de mesnada, traer la definición nebrisense de nava, conocer los cuartetos alejandrinos de Berceo, citar los Fori oscenses Jacobi I. En fin, su amor por la documentación, con apuntes sobre Gonzalo Fernández de Oviedo por ejemplo, y por la literatura castellana, es manifiesto, así como la sensibilidad que demuestra en la copia completa del bellísimo y emocionante Romance del prisionero, con la variante "matómela un caballero" frente a "matómela un ballestero". Pero sus manuscritos también descubren el sentido de corrección idiomática que Bello pretendió inculcar con sus trabajos lingüísticos y gramaticales, así cuando enmienda un efecto en la lengua escrita de la aspiración de la /-s/, "que efor (tachado) esforzándose en sus fuerzas", o la existencia de la desinencia -ite, -ites tanto en el español de Chile como en el de Venezuela ("cuando fuite caballero en el altar de Santiago") ${ }^{13}$.

13 Según Oroz formas frecuentes en todo el sur y centro del país, en Chiloé amates, comites, fuites, trajite (1966: 309), de uso rústico, como son en México y otras partes de América, entre ellas zonas colombianas y venezolanas, existentes en hablas andaluzas y comunes en judeoespañol. En las anotaciones manuscritas conservadas en el Archivo Andrés Bello de la Universidad de Chile se lee también "el color alcaico del original" (MD 772-4), pero seguramente es del amanuense, y sin duda a la pluma de un ayudante de buena letra se debe un devantaba al comienzo de la Relación de los hechos del Cid anteriores a su destierro (MD 772-1), que Bello corrigió levantaba. Para el conocimiento de la personalidad, formación y obra de Bello es recomendable la lectura de Jaksic (2001), y de gran utilidad para la aclaración de estas y otras cuestiones va a ser la transcripción de los Cuadernos de Londres del polígrafo americano, en la que está trabajando un equipo dirigido por este excelente investigador. Por cierto, el caso del bellista efor tachado se corresponde con los cacográficos efuerzos, eforsando, a los que se añade un lloral 'llorar', del amanuense al servicio del andaluz Rafael de Orozco, quien el 27 de enero de 1789 dirige una carta a Miguel de Iribarren, poderoso hombre de negocios en Cádiz, con muchos intereses comerciales en América: Archivo Histórico Provincial de Cádiz, Fundación Luis Goytisolo, Familia Iribarren, expediente 63, caja 1. 


\section{REFERENCIAS BIBLIOGRÁFICAS}

Ayuntamiento de Burgos (ed.). 1988. Poema del Cid, edición facsímil. Vitoria: H. Fournier. Bello, AndRÉs. 2002. Andrés Bello Digital: Obras completas, bibliografía. Biblioteca Virtual Andrés Bello de Polígrafos Hispanoamericanos. Madrid: Fundación Hernando de Larramendi - The King Juan Carlos I of Spain Center of New York University - Fundación MAPFRE TAVERA.

2013. Gramática de la libertad. Textos sobre lengua y literatura. Iván Jaksic, Fernando Lolas y Alfredo Matus Olivier (comps.), Santiago: Fondo de Publicaciones Americanistas y Facultad de Filosofía y Humanidades. Universidad de Chile.

CANellas LóPEZ, ÁNGel. 1972. Un documento soriano romanceado: infeudación del castillo de Alcozar hacia 1156. Homenaje a Francisco Ynduráin, pp. 107-127. Zaragoza: Universidad de Zaragoza.

Corominas, Juan y José A. Pascual. 1980-1991. Diccionario crítico etimológico castellano e hispánico. Madrid: Editorial Gredos.

EnCINA, JuAn DEL. 1496/1981. Cancionero, edición facsímil de la Real Academia Española. Madrid: Arco Libros.

Frago, Juan Antonio. 1989. El marco filológico del Vidal Mayor. Vidal Mayor. Estudios, con facsímil del códice. Agustín Ubieto Arteta (dir.). Madrid: Diputación Provincial de Huesca-R. Díaz-Casariego Editor, pp. 85-112.

1993. Historia de las hablas andaluzas. Madrid: Arco Libros.

1998. El paso del romance a la escritura: problemas culturales y lingüísticos. XXIV

Semana de Estudios Medievales de Estella. Renovación intelectual del Occidente europeo (S. XII). Pamplona: Gobierno de Navarra, pp. 63-98.

2000. Cronología y geografía lingüística en el texto del códice cidiano. En César Hernández Alonso (ed.). Actas del Congreso Internacional "El Cid, poema e historia". Burgos: Amabar S. L., pp. 229-234.

2002. Textos y normas. Comentarios lingüisticos. Madrid: Editorial Gredos.

2008. Sobre disensos acerca de la relación histórica entre el español de España y el de América. BFUCh 43/2: 11-49.

JAKSIC, IvÁn. 2001. Andrés Bello: La pasión por el orden. Santiago: Universidad de Chile.

LAPESA, RAFAel. 1985. Historia de la lengua española. $9^{\text {a }}$ ed. Madrid: Editorial Gredos.

Menéndez Pidal, Ramón. 1971. Crestomatía del español medieval, I. $2^{\text {a }}$ edición, $1^{\text {a }}$ edición de 1964, acabada y revisada por Rafael Lapesa y María Soledad de Andrés. Madrid: Editorial Gredos. Calpe.

1976. Cantar de Mio Cid. Texto, gramática y vocabulario. $5^{\mathrm{a}}$ ed. Madrid: Espasa

1980. Manual de gramática histórica española. Madrid. Espasa Calpe, $16^{\mathrm{a}}$ edición.

Montaner, Alberto (ed.). 1993. Cantar de Mio Cid. Barcelona: Crítica.

Orduna, Germán. 1989. El testimonio del códice de Vivar. Incipit 9: 1-12.

Oroz, Rodolfo. 1966. La lengua castellana en Chile. Santiago. Universidad de Chile.

Tilander, GunNar. 1956. Vidal Mayor. Traducción aragonesa de la obra "In excelsis Dei thesauris de Vidal de Canellas”, II. Texto. Lund: Hákan Ohlssons Boktrickeri. 